\title{
Higienização das mãos: Educação permanente para a família de pacientes em tratamento com a diálise peritoneal
}

RESUMO | Objetivo: identificar a compreensão dos familiares sobre a importância da técnica de higienização das mãos para a realização de diálise peritoneal em domicílio. Metodologia: estudo descritivo, abordagem qualitativa, método de pesquisa convergente-assistencial. O estudo foi realizado em um Hospital Universitário Estadual do Rio de Janeiro, no setor de Nefrologia. O estudo envolveu 06 familiares que realizam terapia de diálise peritoneal para seus familiares. A coleta de dados ocorreu no período de 13 de julho de 2017 a 31 de agosto de 2017. Principais resultados: dos 06 participantes do estudo 02 realizou-se o saneamento das mãos corretamente de acordo com o vídeo fornecido pela pesquisadora. Conclusão: Percebe-se que, para alguns participantes, ainda há receio e insegurança em relação à execução da técnica de higienização das mãos corretamente.

Palavras-chaves: Diálise Peritoneal; Enfermagem; Desinfecção das Mãos.

ABSTRACT I Objective: the present study has the following aims: to identify the family members' understanding of the importance of hand hygiene technique for peritoneal dialysis at home. Methods: a descriptive study, qualitative approach, using Convergence - Assistance Research as a method. The study was conducted at a State University Hospital located in the city of Rio de Janeiro, in the Nephrology sector. Sixty family members undergoing peritoneal dialysis therapy of their relative at home participated in the study. Data collection occurred from July 3, 2017 to August 31, 2017. Results: of the 06 participants in study 02 performed the hand hygiene correctly according to the video provided by the researcher. Conclusion: the study reached the proposed objectives; with this it was perceptible that for some participants there is still fear and insecurity about the execution of the technique of hand hygiene correctly.

Keywords: Peritoneal Dialysis; Nursing; Handwashing.

RESUMEN | Objetivo: identificar el entendimiento de los familiares sobre la importancia de la técnica de higienización de las manos para la realización de la diálisis peritoneal en el domicilio. Metodología: estudio descriptivo, abordaje cualitativo, método la Investigación Convergente-Asistencial. El estudio fue realizado en un Hospital Universitario Estadual de Río de Janeiro, en el sector de Nefrología. Participaron del estudio 06 familiares que realizan la terapia de diálisis peritoneal de su pariente. La recolección de datos ocurrió en el período de 13 de julio de 2017 al 31 de agosto de 2017. Resultados principales: de los 06 participantes del estudio 02 realizaron la higienización de las manos de forma correcta de acuerdo con el vídeo proporcionado por la investigadora. Conclusión principal: Fue perceptible que para algunos participantes aún exista el miedo y inseguridad con relación a la ejecución de la técnica de higienización de las manos de forma correcta.

Descriptores: Diálisis Peritoneal; Enfermería; Lavado de las Manos.

\section{Samanta Nascimento Cesário}

Enfermeira nefrologista pelo Hospital Universitário Pedro Ernesto - Faculdade de Enfermagem da Universidade do Estado do Rio de Janeiro.

\section{Joyce Martins Arimatéa Branco Tavares}

Doutora em enfermagem, professora adjunto da Universidade do Estado do Rio de Janeiro (UERJ), enfermeira do Hospital Universitário Antônio Pedro /Universidade Federal Fluminense (UFF).

\section{Frances Valéria Costa e Silva}

Doutora em enfermagem, professora adjunto da Faculdade de Enfermagem da Universidade do Estado do Rio de Janeiro . FENF- UERJ, coordenadora do ambulatório de diálise peritoneal e de tratamento da doença renal crônica do HUPE / UERJ.

\section{Priscilla Valladares Broca}

Doutora em enfermagem, professora adjunto do Departamento de Enfermagem Fundamental da Escola de Enfermagem Anna Nery/Universidade Federal do Rio de Janeiro.

\section{Viviane Ganem Kipper de Lima}

Mestre em enfermagem, professora assistente da Faculdade de Enfermagem da Universidade do Estado do Rio de Janeiro. FENF- UERJ.

\section{George Roberto Ferreira}

Enfermeiro especialista em Oncologia pela Universidade do Grande Rio - Unigranrio, atualmente é enfermeiro assistencialista pelo Grupo Santa Celina.

Recebido em: 10/05/2019

Aprovado em: 13/05/2019
INTRODUÇÃO

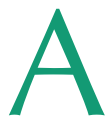
higienização das mãos é reconhecida mundialmente como uma medida primária, mas muito importante no controle de infecções relacionadas à assistência à saúde. Por esse motivo, tem sido considerada como um dos pilares da prevenção e do controle de infecções nos serviços de saúde, incluindo aquelas decorrentes da transmissão cruzada de microrganismos multirresistentes $^{(1)}$.

$\mathrm{Na}$ realização da diálise peritoneal (DP), um dos primeiros passos e, senão, o mais importante, é a higienização das mãos. Através dela, o paciente e o familiar responsável pelo seu cuidado esta- 
rão aptos a realizar as trocas das bolsas, curativos e manusear o cateter de forma correta. A mesma deve ser realizada de acordo com os parâmetros da Agência Nacional de Vigilância Sanitária (ANVI$\mathrm{SA})$ que visa à segurança do paciente $\mathrm{e}$ do método utilizado, refletindo em maior eficácia para o tratamento.

Os pacientes que aderem a DP precisam de um processo de adaptação, estando incluídos o processo educativo do indivíduo e do familiar, consultas mensais para avaliação médica e de enfermagem onde são repassados pelo enfermeiro todo o processo que envolve a DP, ou seja, demonstram se os objetivos da capacitação estão sendo alcançados. Esse processo ocorre por um tempo médio de 1-2 meses até que a pessoa responsável pela realização do tratamento podendo ser o próprio paciente ou familiar se mostre apto a seguir o mesmo em seu domicílio.

Na prática do setor, foi percebido que durante as consultas de enfermagem da diálise peritoneal, quando a familia se faz presente e apoia o paciente, o mesmo se sente mais seguro e confiante a ingressar na terapeutica proposta. Sendo assim, o apoio familiar é importante nos momentos de duvidas e medo, pois tudo é desconhecido.

Para a realização da DP, é necessário que um cateter seja inserido por meio cirúrgico no abdômen do paciente. $\mathrm{O}$ cateter de Tenckhoff é o mais utilizado. Ele é reto e têm dois cuffs, um fica localizado mais profundamente e dentro do músculo reto abdominal e o outro é subcutâneo, aproximadamente $2-3 \mathrm{~cm}$ do orifício de saída. Os cuffs têm a função de proteger o cateter contra a migração bacteriana através da pele pelo trajeto subcutâneo ${ }^{(2)}$.

$\mathrm{O}$ enfermeiro, dentre os profissionais de saúde, é o que atua de modo mais próximo e constante junto aos pacientes. A interação entre o enfermeiro e o paciente que vai iniciar a terapia dialítica dura muitos anos e, por vezes, é bastante intensa. Dessa maneira, no desenvolvimento de práticas educativas, o enfermeiro deve ter, além da fundamentação científica e da competência técnica, conhecimentos dos aspectos que levam em consideração os sentimentos, necessidades e desejos do paciente sob sua orientação. Nesse sentido, não basta um material didático que não promova questionamentos e não origine motivação interna para mudar. Certamente, faz-se necessária essa abertura ao diálogo, a possibilidade do outro se perceber como ser único, embora com vivências comuns aos seus semelhantes ${ }^{(3)}$.

A higienização das mãos é uma técnica que envolve todo o processo da DP, pois a mesma é utilizada desde o momento em que o material é preparado até a troca das bolsas. A realização da técnica de forma correta e efetiva confere segurança ao tratamento evitando que haja contaminação pelos microrganismos que estão presentes na pele do paciente.

O protocolo para prática de higienização das mãos em serviços de saúde do Ministério da Saúde (MS) tem como finalidade instituir e promover a higienização das mãos nos serviços de saúde do país com o intuito de prevenir e controlar infecções relacionadas à assistência à saúde (IRAS), visando à segurança do paciente, dos profissionais de saúde e de todos aqueles envolvidos nos cuidados aos pacientes ${ }^{(1)}$.

A higienização das mãos utilizada na realização da diálise peritoneal está em conformidade com a Comissão de Controle de Infecção Hospitalar (CCIH) da unidade em que o estudo foi realizado, e obedece o Programa Nacional de Segurança do Paciente - (Meta 5) que estabelece e promove a higiene das mãos nos serviços de saúde.

$\mathrm{Na}$ diálise peritoneal, a higienização das mãos, além de ser um procedimento obrigatório para realização do tratamento, previne a contaminação do cateter e infecções, como por exemplo a peritonite, que permanece como a principal complicação do paciente que realiza diálise peritoneal, estando no topo de causas que levam à falência de acesso e insucesso do tratamento. O principal agente infeccioso relacionado à peritonite, no Brasil, é o Staphylococcus aureus, que é fator contribuinte em 16\% dos óbitos e $18 \%$ da mortalidade ${ }^{(4)}$.

Sendo assim, o estudo se justifica pela necessidade de expor aos pacientes e familiares o quanto a higienização das mãos correta influencia de forma positiva no tratamento da DP, permitindo que esta terapia seja executada sem oferecer riscos aos pacientes.

Questões norteadoras: Como identificar o entendimento dos familiares sobre a importância da técnica de higienização das mãos para a realização da diálise peritoneal no domicílio? Como descrever a forma como os familiares realizam a técnica de higienização das mãos para o tratamento com a diálise peritoneal? Como verificar a ocorrência de mudança na forma de fazer a higienização das mãos destes familiares para realização da diálise peritoneal após a utilização de um vídeo explicativo?

Desta forma, os objetivos da pesquisa foram: identificar o entendimento dos familiares sobre a importância da técnica de higienização das mãos para a realização da diálise peritoneal no domicílio; descrever a forma como os familiares realizam a técnica de higienização das mãos para o tratamento com a diálise peritoneal e verificar a ocorrência de mudança na forma de fazer a higienização das mãos destes familiares para realização da diálise peritoneal após a utilização de um vídeo explicativo.

\section{METODOLOGIA}

Estudo descritivo com abordagem qualitativa, onde o método utilizado foi o da Pesquisa Convergente-Assistencial (PCA), que é definida como um tipo de pesquisa empregada nas áreas assistenciais onde se desenvolva uma prática com participação ativa dos sujeitos da pesquisa, estando orientada para a resolução ou minimização dos problemas na prática, ou para a realização de mudanças e/ou introdução de inovações nas práticas de saúde podendo levar a construções teóricas ${ }^{(5)}$.

O estudo ocorreu mediante as etapas propostas pela PCA, que são elas: concepção, instrumentação, perscrutação e análise.

A fase da concepção se relacionou com a origem da pesquisa, mediante definição 
do objeto, objetivos e justificativa do estudo. A fase de instrumentação definiu os procedimentos metodológicos que foram utilizados, delimitou o espaço físico, os participantes envolvidos e os métodos e técnicas para obtenção das informações. O cenário do estudo foi um Hospital Universitário do Estado do Rio de Janeiro, no setor de Nefrologia, especificamente no serviço de Diálise Peritoneal. Até a finalização da coleta de dados, faziam parte do programa de DP 17 pacientes. O serviço contava com uma equipe multiprofissional formada por: uma enfermeira líder, uma técnica de enfermagem, residentes de enfermagem e medicina, médico, nutricionista e psicóloga.

As técnicas para produção de dados foram compostas por observação participante, entrevista individual semiestruturada gravada e preenchimento do roteiro para caracterização do perfil dos participantes da pesquisa que foram os familiares que realizam o tratamento dos pacientes com a diálise peritoneal.

Os critérios de inclusão foram: familiares de ambos os sexos, maiores de 18 anos, que já tivessem recebido ou estivessem em processo de aprendizagem da técnica de DP na atividade educativa de capacitação para início da terapia e que tenham realizado o tratamento do seu parente por no mínimo 06 (seis) meses no domicílio.

Com isso, dos 17 (dezessete) pacientes cadastrados, 04 (quatro) foram excluídos por realizarem a própria terapia, restando 13 (treze) pacientes em que os familiares eram os responsáveis por realizar o tratamento no domicílio. Dos familiares responsáveis pelo tratamento destes 13 (treze) pacientes, apenas 07 (sete) aceitaram participar do estudo. Dos 7 (sete) familiares, 01 (um) desistiu na segunda etapa por problemas de saúde. Foram excluídos 06 (seis) familiares do estudo por não terem comparecido as consultas de enfermagem e médica junto aos seus parentes. Vale ressaltar que cada paciente possui um familiar elegido como responsável pela terapia dialítica. Sendo assim, o total de participantes da pesquisa foram 06 (seis).

A fase de perscrutação foi caracteriza- da pelas estratégias de refinamento da obtenção das informações, como coleta de dados e entrevistas, estando diretamente relacionada ao momento do primeiro e do segundo encontro da pesquisadora com os participantes da pesquisa .

No primeiro momento da produção dos dados, o participante comparecia ao serviço de DP para acompanhamento do seu familiar na consulta de enfermagem, medicina ou para realizar algum atendimento. Com isso, era apresentada a proposta do estudo e perguntado se o mesmo aceitava participar. Em caso positivo, era entregue o Termo de Consentimento Livre e Esclarecido (TCLE) em duas vias, sendo uma delas para a pesquisadora e outra para o participante. $\mathrm{O}$ documento informava detalhadamente os aspectos éticos da pesquisa, incluindo benefícios e possíveis riscos. Vale ressaltar que a pesquisa teve aprovação do Comitê de Ética em Pesquisa (CEP) da instituição que serviu de cenário, obtendo parecer aprovado com número de protocolo: 2.138.707. Todos os aspectos éticos que dizem respeito ao desenvolvimento da pesquisa com seres humanos foram respeitados, garantindo-se a proteção dos direitos dos participantes da pesquisa, conforme preconiza a Resolução n. ${ }^{\circ}$ 466/12 do Conselho Nacional de Saúde (CNS). Sendo assim, iniciou-se o processo de produção dos dados, que ocorreu mediante aplicação dos instrumentos previamente autorizados pelos participantes envolvidos voluntariamente na pesquisa.

A pesquisa consistia em: no primeiro momento, foi preenchido um roteiro de identificação para caracterizar os participantes da pesquisa; no segundo momento, realizou-se uma entrevista individual gravada utilizando um roteiro de entrevistas semiestruturado, previamente elaborado e testado, contendo 11 perguntas relacionadas ao tema central da pesquisa. A coleta de dados ocorreu no período de 03 de julho de 2017 a 31 de agosto de 2017. As entrevistas foram gravadas em aparelho de telefone móvel e, posteriormente, transcritas na íntegra.
Foi iniciada a coleta de dados com o preenchimento do roteiro de identificação e caracterização. Em seguida, era realizada a entrevista semiestruturada gravada com utilização do roteiro de entrevistas. Após, para realização da primeira observação, era solicitado ao participante que demonstrasse para a pesquisadora como o mesmo higienizava as mãos em casa para realizar o tratamento do seu familiar ou como havia aprendido na atividade educativa de capacitação realizada pelo enfermeiro. Nesse mesmo momento, a pesquisadora enquanto observava, realizava os registros em um roteiro de observação participante.

Em seguida, foi disponibilizado ao participante um DVD (digital versatile disc) com um vídeo produzido pela pesquisadora sobre a técnica de higienização das mãos ensinada para a realização da terapia de diálise peritoneal e solicitado ao mesmo que assistisse ao vídeo no domicílio, quantas vezes fosse necessário, para orientar a realização da técnica e esclarecimento de possíveis dúvidas. $\mathrm{O}$ retorno deste participante foi agendado para 30 (trinta) dias após a primeira etapa de coleta de dados, coincidindo com a data de retorno mensal das consultas de enfermagem e médica.

No retorno dos participantes para a segunda observação, foi pedido aos mesmos que realizassem a técnica de higienização das mãos mediante ao que tinham assistido no vídeo para avaliar a aprendizagem e o impacto deste como ferramenta educativa. Nesta observação, também foi preenchido um roteiro para que a pesquisadora pudesse comparar com a observação anterior e avaliar se houve mudanças na execução da técnica de higienização das mãos.

Com relação a análise dos dados, a mesma ocorreu mediante as etapas preconizadas pela PCA. Desta forma, no processo de apreensão, os dados foram organizados para facilitar sua codificação, reconhecendo no relato das informações as palavras, frases, parágrafos ou termos chave que mais se repetiam nas falas dos participantes. Após essa codificação, teve início a formação das categorias empíricas, que são o conjunto de expressões 
com características similares ou que possuem estreita relação de complementaridade para fornecer por condensação uma representação simplificada dos dados brutos, seguida da aplicação da técnica de análise de conteúdo. Todo material gerado na coleta de dados foi submetido à técnica de análise de conteúdo, com vistas a manutenção da coerência durante o processo de análise ${ }^{(6)}$.

Foram utilizados pseudônimos para identificar os participantes e garantir, assim, o seu anonimato através da utilização de nomes de cores, como por exemplo: azul, amarelo, verde, etc.

\section{RESULTADOS}

Os resultados obtidos mediante a aplicação do roteiro de caracterização dos participantes da pesquisa revelaram que 05 (cinco), dos 06 (seis) participantes eram do sexo feminino e todos se autodeclararam brancos na cor da pele. A média de idade variou entre 24 e 64 anos, sendo 01 (um) com 24 (vinte e quatro) anos, 01 (um) com 32 (trinta e dois) anos, 01 (um) com 48 (quarenta e oito) anos , 01 (um) com 54 (cinquenta e quatro) anos , 01 (um) com 63( sessente e três) anos e 01 (um ) com 64 (sessenta e quantro anos) com grau de parentesco relacionado à família nuclear, ou seja, pai, esposas e filhas. Todos participantes declararam possuir renda própria e terem como cidade natal e residência o município do Rio de Janeiro. Apenas 01 (um) participante declarou não morar na mesma residência que o seu familiar. Quanto ao estado civil, 02 (dois) participantes são solteiros, 03 (três) casados e 01 (um) divorciado. 05 (cinco) participantes declararam ter filhos. Com relação à religião, 03 (três) informaram ser católicos e 03 (três) evangélicos.

O tempo de participação no programa de Diálise Peritoneal variou de 01 mês a 01 ano, sendo que 01 (um) participante estava em break in no momento da coleta de dados, que é o período em que o paciente já realizou a inserção do cateter de Tenckhoff, porém, ainda está em treinamento para início da terapia no domicílio. Desta forma, dos 05 (cinco) participantes em que seu parente realiza a terapia dialítica, 03 (três) fazem a modalidade automatizada e 02 (dois) intercalam entre automatizada e manual.

Após análise do conteúdo da técnica de higienização das mãos dos participantes antes e após a aplicação do vídeo educativo, foram percebidas similaridades e divergências nas falas e no modo como os participantes as executavam. Através disso foi gerada uma matriz temática sendo dividida em duas categorias: O processo de higienização das mãos para diálise peritoneal antes da execução do vídeo educativo e a ocorrência de mudanças na técnica de higienização das mãos após aplicação do vídeo educativo.

O processo de higienização das mãos para diálise peritoneal antes da execução do vídeo educativo

A realização das entrevistas e das observações sistemáticas antes e após a utilização do vídeo mostrou o entendimento de 03 (três) dos familiares sobre o que é a terapia dialítica, sua finalidade e a importância da higienização das mãos para que a terapia seja executada de forma correta e segura contribuindo para manutenção da saúde do seu familiar.

"A higienização das mãos é muito importante, é a questão da segurança principalmente do paciente quanto da pessoa que está cuidando dele, porque o risco de uma infecção pode ser a qualquer momento" (Rosa).

Em relação aos familiares responsáveis pela execução do tratamento, quando questionados sobre o motivo pelo qual realizam a terapia do seu parente, 04 (quatro) responderam que o fazem por escolha, porém são as únicas pessoas disponíveis para realização do tratamento, o que traz à tona uma imposição velada. Somente 02 (dois) participantes responderam que exercem o tratamento por não ter opção.
"Por não ter opção, porque sou a esposa dele e sou a única pessoa disponível para realizar o tratamento" (Lilás).

Durante a observação sistemática realizada antes do fornecimento do vídeo, verificou-se que no entendimento de alguns participantes o número de vezes que higienizam as mãos é mais importante do que a forma como elas são higienizadas, ou seja, se um familiar higienizou as mãos 03 vezes e realizou cada passo 10 vezes no seu entendimento elas estão limpas, não importando se o passo 03 foi executado no lugar do passo 02 . Esse tipo de falha foi encontrado em 03 dos 06 participantes.

A ocorrência de mudanças na técnica de higienização das mãos após aplicação do vídeo educativo

Na realização da segunda observação sistemática após o fornecimento do vídeo, dos 06 (seis) participantes do estudo apenas 02 (dois) executaram a higienização das mãos de forma correta de acordo com o preconizado pela terapia, o que pode ser explicado pelo fato dos participantes não terem assistido ao vídeo ou terem assisto e não assimilado o conteúdo do mesmo. Como referido anteriormente, durante a entrevista semiestruturada, quando perguntado sobre o motivo pelo qual realizam a terapia do seu parente, 04 (quatro) deles responderam por não ter opção ou porque são as únicas pessoas que eles possuem para serem responsáveis pelos cuidados, ou seja, muitas vezes realizam o treinamento/capacitação por falta de opção ou por uma imposição velada, o que pode causar um bloqueio nesse processo de educação em saúde.

Com relação ao processo de capacitação dado pelo enfermeiro, os 06 (seis) participantes expressaram satisfação e demonstraram interesse pelo aprendizado e oportunidade de compartilhar conhecimentos com a pesquisadora. 
"Eu achei excelente, adore mesmo, eu gostei de ter visto, gostei de ter aprendido, a cada dia mais eu quero aprender para ajudar meu paciente" (Vermelho).

No processo da diálise peritoneal, a higienização das mãos é primordial para o sucesso da terapia e, embora os participantes da pesquisa sintam dificuldade de adaptação a terapia dialítica no domicílio, quando questionados em relação à higienização das mãos para a realização do tratamento, os 06 (seis) participantes informaram saber da importância desta etapa para o sucesso da terapia.

"É $90 \%$ do sucesso da DP, porque sem a higienização pode ocasionar muitas outras coisas para ela. É uma coisa que seria a solução e acaba sendo o problema" (Marrom).

\section{DISCUSSÃO}

Embora existam evidências de que higienizar as mãos corretamente consiste em uma medida indispensável para reduzir a transmissão de microorganismos por meio das mãos, a adesão a esta prática permanece baixa e estudos relatam taxas inferiores a $60 \%$ em diferentes realidades de assistência à saúde ${ }^{(7)}$.

Durante o processo de capacitação/ treinamento, o enfermeiro é o responsável pelo ensinamento, por mostrar técnicas que deverão ser executadas de forma segura, por construir um vínculo onde o familiar responsável sinta-se seguro para expor seus medos, inseguranças e dúvidas mediante ao que está sendo ensinado e vivenciado e o que se pode esperar futuramente. É um processo em que é importante seguir etapas, pois a partir disso, ele poderá entender que mudanças e adaptações precisarão ser feitas.

O processo de capacitação depende de como o familiar entende o que é ensinado em cada etapa e se mediante a isso saberá executá-lo de forma correta. Em alguns mo- mentos este processo pode não estar claro e o familiar não sanar possíveis dúvidas, executando com o passar do tempo a técnica da forma que acha ser correta. Caso identifique que esta atitude não ocasionou dano a saúde, começam a tornar o uso da técnica incorreta um hábito, comprometendo a terapia e trazendo riscos para o paciente.

Por isso, é necessário que o familiar crie vínculo e confie no enfermeiro que o está capacitando, da mesma forma que o enfermeiro precisa entender as limitações e identificar as potencialidades deste familiar, em constante movimento de troca e compartilhamento, pois a terapia dialítica é algo novo e, por muitas vezes, um desafio, cabendo ao enfermeiro entender que para cada família existe um tempo certo, cada ser é único e o tempo de aprendizagem de um familiar não é o mesmo do outro. O enfermeiro deve saber distinguir a forma de abordagem correta para que no futuro não traga riscos para ambos, paciente e família.

A higienização das mãos é um processo mundialmente conhecido por evitar riscos ao paciente e cuidador, sendo a primeira medida adotada em qualquer cuidado à saúde. Durante a capacitação/treinamento da diálise peritoneal, ela é primeira etapa a ser aprendida e, apesar de ser a forma mais eficaz e simples de evitar a transmissão de doenças, é onde encontra-se maior dificuldade durante o aprendizado.

A higienização das mãos vem sendo reconhecida e recomendada desde 1846 como prática obrigatória para os profissionais da área da saúde, com base na constatação de sua efetividade na redução das infecções e, consequentemente, de mortalidade entre os pacientes. Com a introdução das práticas de higienização das mãos, a redução imediata da microbiota transitória tem sido verificada. Desde então, estudos sobre a transmissão de microrganismos, tendo as mãos dos profissionais como carreadoras, têm sido frequentes. Atualmente, sabe-se que a higienização das mãos reduz a transmissão de patógenos e, sobretudo, a incidência de infecções relacionadas ao cuidar em saúde (IRCS), sendo considerada uma medida simples e importante ${ }^{(8)}$.

Um estudo realizado em uma unidade de terapia intensiva de um Hospital Universitário na Alemanha fez uma comparação entre médicos e enfermeiros e sua crença em relação de que a desinfecção das mãos impede a transmissão de patógenos. Os resultados mostraram que primeiro, os enfermeiros perceberam redução de risco associado à higiene das mãos, e indicou melhor conhecimento sobre diretrizes de higiene das mãos do que os médicos, essa questão ainda é consistente com maiores taxas de adesão relatadas para os enfermeiros na literatura. Desta forma, o estudo pode mostrar que a promoção eficaz da higienização das mãos pode implicar tanto em medidas educativas quanto em treinamento de habilidades ${ }^{(9)}$.

Analisando as observações sistemáticas após o vídeo, identificou-se que os familiares participantes que realizam a terapia do seu parente por um tempo prolongado adquirem segurança e realizam a higienização das mãos baseada em um saber leigo. Eles percebem que com o tempo realizando a técnica da forma como acham mais adequada não causam danos ao paciente e isso acaba tornando-se um hábito.

Por outro lado, ficou claro que para 02 (dois) familiares a higienização das mãos é importante e está incluída na sua rotina, porém de forma errada. Existem situações em que o hábito de higienizar as mãos torna-se vicioso e, se executado de forma correta e excessiva, pode trazer danos à saúde do familiar, como por exemplo, a destruição da microbiota residente.

Em outro contexto, pode-se citar a questão do ser humano ao ser apresentado a algo novo e sua adaptação mediante a sua responsabilidade sobre isso. O homem, por sua constituição psíquica, mental, espiritual e física, é um ser adaptável a todas as mudanças e a todas as situações em que a vida o coloca, à medida que avança para seu aperfeiçoamento. Pode-se dizer que é geral - visto que se produz em todos - a reação que o ser experimenta quando, premido pelas circunstâncias, deve aceitar situações às quais, por vonta- 
de própria não haveria jamais tratado de se adaptar. O tempo, com a série de reflexões que sustenta em seus poderosos meios de expressão, faz com que o homem admita, aceite e se adapte a mudanças e a situações, mas sem alcançar - salvo exceções - a compreensão exata de tais fatos. Daí a diferença entre os que se adaptam por obrigação e os que buscam a adaptação natural, com plena noção do que isso significa para seu processo evolutivo ${ }^{(10)}$.

Por este e por outros fatores é importante que os familiares que passam pelo processo de treinamento/capacitação tenham em mente que o cuidado que deverá ser realizado em todas as etapas do tratamento, visando evitar infecções e outras possíveis complicações, reforçando a questão da técnica adequada de higienização das mãos, que é o primeiro passo para a realização da DP e que acontece em todo o momento, desde a separação e limpeza do material até o preparo da terapia, conexão e desconexão do paciente na máquina de DP. Esta técnica é importante para a segurança do paciente e para a o sucesso do tratamento.

Desta forma, o estudo confirmou o quanto a educação permanente que o enfermeiro promove pode influenciar de forma positiva na vida do paciente e familiares e estará ligada diretamente ao sucesso do tratamento, melhorando a adesão à terapia e aumentando o conhecimento de ambos sobre a DP e tudo que a cerca.

Quanto à limitação do estudo, está relacionada ao fato da pesquisa ter sido realizada em um único serviço de DP e ter tido um número reduzido de participantes pelo próprio perfil da institução.

\section{CONCLUSÃO}

A higienização das mãos é e sempre será importante para os cuidados de saúde e, embora seja uma tarefa difícil torná-la um hábito diário, é necessário que o enfermeiro como gestor de cuidado e educador em saúde reforce a sua importância para que se torne uma prática cada vez mais forte e seja agregada a rotina de pacientes e familiares.

A Pesquisa Convergente-Assistencial contribuiu para a obtenção de informações relevantes acerca desse cuidado, sendo fundamental para a produção dos dados, principalmente, durante a coleta dos mesmos, pois, além de proporcionar maior interação entre os participantes da pesquisa, permitiu que eles revelassem objetivamente suas vivências e experiências. O estudo conseguiu alcançar os objetivos propostos e, com isso, foi perceptível que para alguns participantes ainda existe o medo em relação à execução da técnica de higienização das mãos de forma incorreta e insegurança em saber que podem causar dano ao seu parente.

Por outro lado, existe o excesso de segurança em perceberem que durante o período em que executaram a higienização das mãos de forma errada, seja quebrando a técnica ou realizando o passo a passo da mesma fora da sequência, não causou danos permanentes, dando continuidade desta forma ao erro. Tal situação foi perceptível em familiares que realizam a terapia do seu parente por um longo período, ao contrário dos familiares que estão no início da terapia, onde existe uma insegurança de iniciante, em saber se está realizando de forma correta ou não a técnica.

A utilização da Pesquisa Convergente Assistencial como método foi positiva para o estudo, porque houve proximidade entre a pesquisadora e os participantes, que puderam compreender como é importante a junção da prática e teoria na aplicação do processo de cuidado e educação em saúde. Desta forma, a pesquisadora se comprometeu em fornecer o vídeo para o setor como ferramenta de educação em saúde para os familiares e pacientes que estão no período de capacitação para aprimorar o seu aprendizado.

\section{Referências}

1. Agência Nacional de Vigilância Sanitária. Resolução n. ${ }^{\circ} 36$, de 25 de julho de 2013. Aprova o Protocolo Nacional de Segurança do Paciente. Diário Oficial da União [Internet] [acesso em 10 de junho de 2016]. Disponível em: http:// www20.anvisa.gov.br/segurancadopaciente.

2. Neto OMV, Dantas M. Princípios da diálise peritoneal. Diálise peritoneal: manual prático - Uso diário, ambulatorial e hospitalar. São Paulo: Balieiro; 2013.

3. Dias AC, Prado JP, Hericku O, Galdino GS. 0 papel do enfermeiro na prevenção da peritonite: revisão integrativa. Revista de Enfermagem da Universidade Federal de Pernambuco Online [Internet]. 2014 [acesso em 30 de março de 2017]; 8(7). Disponível em: https://periodicos.ufpe.br/revistas/revistaenfermagem/article/download/9893/10149.

4. Figueiredo AE, Poli CE, Meneghetti F, Lise GAP, Detofoli CC, Silva LB. Peritonites em pacientes em diálise peritoneal: análise de um centro brasileiro segundo as recomendações da Sociedade Internacional de diálise peritoneal. Jornal Brasileiro de Nefrologia - JBN [Internet]. 2013 [acesso em 22 de julho de 2016]; 35(3). Disponível em: http://www.scielo.br/pdf/jbn/v35n3/ v35n3a08.pdf.

5. Trentini M, Paim L, Silva DGV. A convergência de concepções teóricas e práticas de saúde: uma reconquista da Pesquisa Convergente-Assistencial. Porto
Alegre: Moriá; 2017.

6. Bardin L. Análise de Conteúdo. São Paulo: Edições 70; 2011.

7. Giordani AT, Sonobe HM, Ezaías GM, Valério MA, Andrade D. Adesão da equipe de enfermagem à higienização das mãos: fatores motivacionais. Revista da Rede de Enfermagem do Nordeste - RENE [Internet]. 2014 [acesso em 5 de agosto de 2016]; 14. Disponível em: https://www.fen.ufg.br/fen_revista/ v12/n2/v12n2a06.htm.

8. Oliveira $A C$, Paula AO. Monitoração da adesão à higienização das mãos: uma revisão de literatura. Revista Acta Paul Enfermagem [Internet]. 2011 [acesso em 5 de agosto de 2016]; 24. Disponível em: http://www.scielo.br/ scielo.php?script=sci_arttext\&pid=S0103-21002011000300016.

9. Lutz B, Chaberny IF, Graf K, Krauth C, Lange K, Schwadtke L, Stahmeyer J, Lengerke $T$. Intensive care physicians' and nurses' perception that hand hygiene prevents pathogen transmission: Belief strength and associations with other cognitive factors. Journal of Health Psychology [Internet] 2017 [acesso em: 24 de março de 2018]; 22(1). Disponível em: https://www.ncbi.nlm.nih. gov/pubmed/26253651.

10. Pecotche CBG. Introdução ao conhecimento logosófico [Internet]. São Paulo: Fundação Logosófica, 2011. p.161 [acesso em: 22 de março de 2018]. Disponível em: https://www.ncbi.nlm.nih.gov/pubmed/26253651. 